\section{Utilidad de los estudios en busca de autoinmunidad en pacientes con urticaria crónica espontánea}

\section{RESUMEN}

Antecedentes: la urticaria crónica espontánea es una enfermedad común en los adultos, sobre todo entre las mujeres; esta entidad con frecuencia está relacionada con padecimientos autoinmunitarios.

Objetivo: evaluar, mediante estudios de laboratorio, si los pacientes con urticaria crónica espontánea tuvieron signos de autoinmunidad.

Material y método: estudio transversal de 35 pacientes del área de Alergia e Inmunología del Hospital Juárez de México, diagnosticados con urticaria crónica espontánea. Se les realizó biometría hemática completa, anticuerpos antitiroideos (antiperoxidasa y tiroglobulina), anticuerpos antinucleares, factor reumatoide, anticoagulante lúpico, células LE, prueba cutánea de suero autólogo (Autologus Serum Skin Test, ASST), complemento (C3 y C4); como estudios adicionales se les realizó prueba de Helicobacter pylori, perfil tiroideo (T3,T4, TSH) y dímero D.

Resultados: evaluamos 35 pacientes adultos, 27 eran mujeres. La prueba ASST fue positiva en cuatro pacientes, los anticuerpos antinucleares fueron negativos en todos los casos, pero los anticuerpos antitiroideos resultaron positivos en cuatro pacientes. Las células LE, anticoagulante lúpico, complemento, dímero D, perfil tiroideo y Helicobacter pylori fueron normales o negativos y el factor reumatoide fue positivo en un paciente. Todos los pacientes antitiroideos positivos eran mujeres y de ellas, 26 tuvieron ASST negativa. La correlación entre ASST y AAT no fue significativa.

Conclusiones: en nuestro estudio, la mayoría de los pacientes con urticaria crónica espontánea eran mujeres y sólo cuatro tuvieron la prueba ASST positiva, pero esto no se correlaciona con existencia de anticuerpos antitiroideos. La mayor parte de los estudios realizados resultaron normales, por lo que sugerimos no hacer estudios de laboratorio innecesarios en esta afección.

Palabras clave: urticaria crónica espontánea, autoinmunidad, anticuerpos, anticuerpos antitiroideos, prueba cutánea de suero autólogo, roncha, prurito.

\section{Usefulness of studies looking for autoimmunity in patients with spontaneous chronic urticaria}

\section{ABSTRACT}

Background: Chronic spontaneous urticaria (CSU) is a common condition in adults, especially among women; this entity is frequently associ-
María Isabel Rojo-Gutiérrez ${ }^{1}$

Christian Nataly Flores-Ruvalcaba²

Jaime Mellado-Ábrego ${ }^{1}$

Gloria Castillo-Narváez ${ }^{1}$

Danika Pammela Ramírez-Rojo 3

${ }^{1}$ Servicio de Alergia e Inmunología.

${ }^{2}$ Residente de último año de la Especialidad de Dermatología.

Hospital Juárez de México, Secretaría de Salud, México, DF.

${ }^{3}$ Escuela Superior de Medicina, Instituto Politécnico Nacional, México, DF.

Recibido: 6 de enero 2015

Aceptado: 24 de marzo 2015

Correspondencia: Dra. María Isabel Rojo Gutiérrez

Pafnuncio Padilla 10, cuarto piso 53100 Naucalpan de Juárez, Estado de México, México

mi_rojo@yahoo.com.mx

Este artículo debe citarse como

Rojo-Gutiérrez MI, Flores-Ruvalcaba CN, MelladoÁbrego J, Castillo-Narváez G, Ramírez-Rojo DP. Utilidad de los estudios en busca de autoinmunidad en pacientes con urticaria crónica espontánea. Revista Alergia México 2015;62:175-181. 
ated with autoimmune diseases. Our goal is to assess through laboratory studies whether patients with autoimmune CSU presented data.

Material and method: A cross-sectional study of 35 patients was done in the area of Allergy and Immunology at Hospital Juarez de Mexico diagnosed with CSU. We performed the following tests: complete blood count, thyroid antibodies (antiperoxidase and thyroglobulin), antinuclear antibodies, rheumatoid factor, lupus anticoagulant, LE cells Autologous Serum Skin Test (ASST), add (C3 and C4). In addition, we made Helicobacter pylori test, thyroid hormones (T3, T4, TSH) and D-dimer.

Results: We evaluated 35 adult patients, 27 female; ASST was positive in 4 patients, negative antinuclear antibodies in all cases, but positive anti thyroid (AAT) antibodies in 4. The LE cell, lupus anticoagulant, complement, dimer D, thyroid and Helicobacter pylori profile were normal or negative and rheumatoid factor was positive in one patient. All AAT-positive patients were women, but 26 of them had negative ASST. The correlation between ASST and AAT was not significant.

Conclusion: Most patients were women UCE and only 4 had positive ASST, but this does not correlate with the presence of anti-thyroid antibodies. Most studies were normal, so we suggest not making unnecessary laboratory studies in this disease.

Key words: chronic spontaneous urticaria, autoimmunity, antibodies, antithyroid antibodies, autologous serum skin test, weal, pruritus.

\section{ANTECEDENTES}

La urticaria es una reacción delimitada de la piel que se distingue por la rápida aparición de lesiones Ilamadas ronchas o habones; tiene características específicas, como elevación central de la dermis por edema, diámetro variable, halo eritematoso; se asocia con prurito y tiene una duración estimada de 1 a 24 horas; en ocasiones se acompaña de angioedema.

La urticaria crónica es una de las dermatosis más comunes por las que se acude a consulta general y especializada, tiene una prevalencia estimada de 0.5 a $5 \%$ e incidencia estimada de 15 a $25 \%$ en población general. Aparece con mayor frecuencia en adultos, principalmente del sexo femenino, y afecta de 0.1 a $3 \%$ de niños en edad preescolar. ${ }^{1-3}$
La urticaria, al igual que la mayor parte de las enfermedades, se clasifica según su tiempo de evolución, dividiéndose en dos grandes grupos: aguda, con una duración máxima de seis semanas, y crónica, cuya duración es mayor de seis semanas. En la categoría de urticaria crónica se diferencian, a su vez, dos tipos: urticaria crónica continua, con brotes diarios, y urticaria crónica recurrente, con brotes que se repiten a lo largo del tiempo, pero su duración es limitada. ${ }^{4-6}$

De acuerdo con la bibliografía actual, se acordó ampliar la clasificación clásica por una que incluya la patogenia y los estímulos desencadenantes (Cuadro 1).7,8

Los síntomas han sido difíciles de evaluar a lo largo de los años, por lo que de los nuevos lineamientos mundiales surgieron dos escalas que 
Cuadro 1. Clasificación de la urticaria

\begin{tabular}{|c|c|}
\hline Tipo de urticaria & Duración \\
\hline \multicolumn{2}{|l|}{ A. Urticaria espontánea } \\
\hline 1. Urticaria aguda & $<6$ semanas \\
\hline 2. Urticaria crónica & $>6$ semanas \\
\hline Urticaria crónica continua & Lesiones diarias \\
\hline Urticaria crónica recurrente & $\begin{array}{l}\text { Lesiones con intervalos } \\
\text { libres durante días o } \\
\text { semanas }\end{array}$ \\
\hline Tipo de urticaria & Factor desencadenante \\
\hline \multicolumn{2}{|l|}{ B. Urticaria física } \\
\hline 1. Urticaria dermográfica & $\begin{array}{l}\text { Fuerza mecánica sobre } \\
\text { una zona determinada }\end{array}$ \\
\hline $\begin{array}{l}\text { 2. Urticaria retardada por } \\
\text { presión }\end{array}$ & $\begin{array}{l}\text { Presión vertical sobre } \\
\text { una zona determinada }\end{array}$ \\
\hline 3. Urticaria por frío & $\begin{array}{l}\text { Contacto con elementos } \\
\text { fríos }\end{array}$ \\
\hline 4. Urticaria por calor & Contacto con calor local \\
\hline 5. Urticaria solar & $\begin{array}{l}\text { Contacto con luz UV o } \\
\text { luz visible }\end{array}$ \\
\hline 6. Urticaria vibratoria & $\begin{array}{l}\text { Contacto con fuerza } \\
\text { vibratoria }\end{array}$ \\
\hline \multicolumn{2}{|l|}{ C. Tipos especiales de urticaria } \\
\hline \multicolumn{2}{|l|}{ 1. Colinérgica } \\
\hline \multicolumn{2}{|l|}{ 2. Adrenérgica } \\
\hline \multicolumn{2}{|l|}{ 3. Por contacto } \\
\hline 4. Acuagénica & \\
\hline
\end{tabular}

Modificado de la referencia 8.

tienen carácter subjetivo, pero dan pauta para la autoevaluación: la escala de severidad de la urticaria evaluada en siete días, denominada UAS7, y la escala de calidad de vida, llamada CU-Q2oL.

La escala UAS7 evalúa la roncha de acuerdo con la cantidad de lesiones, donde 0 equivale a la ausencia de ronchas, 1 a la existencia de menos de 20 ronchas, 2 a 20-50 ronchas y 3 a más de 50 ronchas. UAS7 también evalúa la existencia de prurito, que se califica de la misma manera: 0 equivale a la ausencia de prurito, 1 a prurito leve, que está presente pero no representa problema para las actividades cotidianas del paciente; 2 equivale a prurito moderado, que representa un problema para la calidad de vida, pero no interfiere con las actividades diarias o con el sueño; por último está el grado 3, que equivale a prurito intenso, que interfiere con las actividades diarias y con el sueño del paciente.

La escala CU-Q2oL califica la calidad de vida y consta de 23 ítems que evalúan seis áreas principales, constituidas por: prurito (dos ítems), repercusión en las actividades de la vida (seis ítems), problemas para dormir (cinco ítems), límites (tres ítems), apariencia (cinco ítems) e hinchazón (dos ítems).

La urticaria crónica tiene una duración mayor a seis semanas; cuando no se identifica un factor desencadenante, se considera urticaria espontánea, que puede ocurrir en $80 \%$ de los casos, de los que 30 a $45 \%$ son de origen autoinmunitario.

Las enfermedades autoinmunitarias asociadas con más frecuencia son enfermedades tiroideas, lupus eritematoso, dermatomiositis, vitíligo, etc.9-11

La evidencia de procesos autoinmunitarios en cuadros de urticaria crónica espontánea se logra demostrar por la existencia de anticuerpos IgG dirigidos contra los receptores alfa de alta afinidad de IgE (FcERI) o contra la misma IgE; estos autoanticuerpos son capaces de estimular a los basófilos y mastocitos para la liberación de mediadores preformados, como histamina, TNF- $\alpha$, IL-3, 4, 5, 6, 8, 13 y factores estimulantes de colonias de granulocitos y macrófagos, mediadores de nueva síntesis a partir del ácido araquidónico que incluyen PGD2 y leucotrienos. Estas citocinas causan aumento en la expresión de moléculas de adhesión en el endotelio de las vénulas poscapilares, lo que puede conducir a infiltración de células en este tejido; además, las aminas vasoactivas favorecen pérdidas transitorias de plasma y mayor reclutamiento de células inflamatorias en piel lesionada. La respuesta tisular urticariana puede ocurrir en menor extensión por neutrófilos y eosinófilos, lo que guarda una posible asociación con enfermedades reumáticas. ${ }^{1,4,5,10,12}$ 
Se ha observado aumento en la prevalencia de enfermedades autoinmunitarias en pacientes con urticaria crónica recurrente; aproximadamente 12 a 19\% de estos pacientes tienen autoinmunidad tiroidea, que debe ser confirmada por la existencia de anticuerpos antitiroideos (antitiroglobulina y antiperoxidasa), porque algunos de estos pacientes pueden o no tener el cuadro clínico característico de estas enfermedades; el tratamiento con tiroxina en algunas ocasiones puede conducir al alivio del cuadro de urticaria; sin embargo, en otros reportes las hormonas tiroideas no están alteradas y el tratamiento con ellas no modifica la evolución del cuadro. ${ }^{10-14}$

Existen otras pruebas de laboratorio que permiten identificar la enfermedad inmunológica primaria por la que aparece el cuadro de urticaria; estas pruebas pueden ser específicas, como la determinación del factor reumatoide y el anticoagulante lúpico; como inespecífica está la prueba de suero autólogo o ASST (del inglés Autologus Serum Skin Test). Esta prueba tiene sensibilidad de $70 \%$ y especificidad de $80 \%$ y es un estudio útil para el rastreo in vivo de la existencia de autoanticuerpos en suero de pacientes afectados; estos anticuerpos son capaces de favorecer la liberación de histamina.

Los pacientes con urticaria crónica espontánea con prueba ASST positiva tienen más probabilidades de padecer enfermedades autoinmunitarias, cursan con una enfermedad más prolongada y pueden ser menos sensibles al tratamiento con antihistamínicos $\mathrm{H} 1$ que aquéllos con prueba ASST negativa. ${ }^{7,9,15,16}$

La identificación temprana de las entidades autoinmunitarias que provocan urticaria ayuda a mejorar de manera significativa la calidad de vida de los pacientes que padecen urticaria crónica, ${ }^{17}$ por lo que es necesario realizar las pruebas pertinentes para su determinación y tratamiento rápido.
En otro estudio nacional, con población similar en número y en características de grupo, se encontró que más de la mitad de los pacientes con urticaria crónica tuvo prueba de Helicobacter positiva y que $11 \%$ de los controles sanos la tuvo positiva; por este motivo se incluye aún en la batería de múltiples estudios.

El objetivo de este trabajo fue determinar si los estudios básicos de laboratorio para determinar autoinmunidad son útiles en pacientes con urticaria crónica espontánea.

\section{MATERIAL Y MÉTODO}

Estudio retrolectivo, longitudinal, en el que se incluyeron pacientes del servicio de Alergia e Inmunología del Hospital Juárez de México que ingresaron con el diagnóstico de urticaria crónica espontánea y que firmaron consentimiento informado, durante un periodo de un año (enero de 2013 a enero de 2014), sin distinción de género ni edad. A todos los pacientes se les realizó biometría hemática completa, anticuerpos antitiroideos (antiperoxidasa y antitiroglobulina), anticuerpos antinucleares, factor reumatoide, anticoagulante lúpico, células LE, prueba cutánea de suero autólogo (ASST) y complemento (C3 y C4). Como estudios adicionales se les realizó prueba de Helicobacter pylori, perfil tiroideo (T3,T4, TSH) y dímero D.

Los resultados obtenidos se analizaron mediante estadística descriptiva y pruebas de correlación de Pearson y Spearman.

\section{RESULTADOS}

Se evaluaron 35 pacientes; la distribución por sexo de los pacientes se muestra en el Cuadro 2.

El intervalo de edad en la que apareció la urticaria principalmente fue entre 41 y 50 años (Figura 1). 
Cuadro 2. Sexo de los pacientes analizados

\begin{tabular}{lc} 
& Frecuencia \\
\hline Femenino & 27 \\
Masculino & 8 \\
Total & 35
\end{tabular}

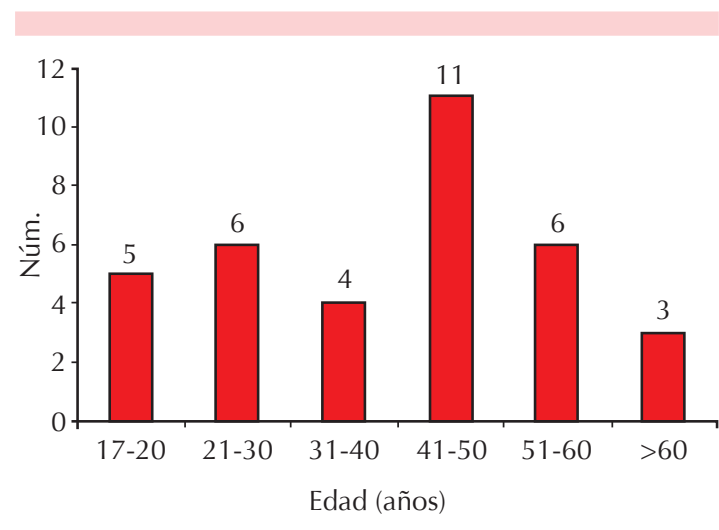

Figura 1. Distribución de los pacientes por edad.

Al evaluar la severidad de la urticaria con la escala UAS7 encontramos que está dividida en evaluación de ronchas -donde se encontró que 10 de 35 pacientes tuvieron cuadros leves, 9 de 35 pacientes tuvieron cuadros moderados y 16 de 35 pacientes tuvieron cuadros severos- $y$ en evaluación del prurito, donde la mayoría de los pacientes (19) tuvo prurito severo, 15 de 35 pacientes tuvieron prurito moderado y sólo un paciente tuvo prurito leve (Cuadro 3).

En cuanto a los estudios inmunológicos realizados, la prueba de suero autólogo (ASST) resultó positiva en 4 de 35 pacientes (Cuadro 4); los

Cuadro 3. Prueba UAS7: ronchas y prurito

\begin{tabular}{lccc}
\hline Roncha & Núm. & Prurito & Núm. \\
Leve & 10 & Leve & 1 \\
Moderado & 9 & Moderado & 15 \\
Severo & 16 & Severo & 19 \\
Total & 35 & Total & 35
\end{tabular}

Cuadro 4. Resultados de suero autólogo

\begin{tabular}{lcccc}
\hline ASST & Frecuencia & Porcentaje & $\begin{array}{c}\% \\
\text { válido }\end{array}$ & $\begin{array}{c}\% \\
\text { acumulado }\end{array}$ \\
\hline Negativo & 31 & 89 & 89 & 89 \\
Positivo & 4 & 11 & 11 & 100 \\
Total & 35 & 100 & 100 & \\
\hline
\end{tabular}

anticuerpos antitiroideos resultaron positivos igualmente en 4 de 35 pacientes (Cuadro 5) y el factor reumatoide fue positivo en un paciente (Cuadro 6). Además, en todos los pacientes hubo negatividad en las pruebas: células $L E$, anticuerpos antinucleares, complemento (C3, C4), dímero $\mathrm{D}$, anticoagulante lúpico, Helicobacter pylori y T3, T4 y TSH (Cuadro 7). En cuanto a los resultados de biometría hemática, se encontró que todos los pacientes tuvieron cifras normales de linfocitos y neutrófilos, y sólo 3 de 35 pacientes tuvieron valores anormales altos de eosinófilos.

La cuantificación de IgE fue normal en 24 de 35 pacientes y el resto tuvo más de $100 \mathrm{Ul} / \mathrm{mL}$ (Figura 2).

Se realizaron pruebas de correlación de Pearson y de Spearman para variables no paramétricas y

Cuadro 5. Resultados de anticuerpos antitiroideos

\begin{tabular}{lcccc}
\hline $\begin{array}{l}\text { Anticuerpos } \\
\text { antitiroideos }\end{array}$ & Frecuencia Porcentaje & $\begin{array}{c}\% \\
\text { válido }\end{array}$ & $\begin{array}{c}\% \\
\text { acumulado }\end{array}$ \\
Negativo & 31 & 89 & 89 & 89 \\
Positivo & 4 & 11 & 11 & 100 \\
Total & 35 & 100 & 100 & \\
& & & &
\end{tabular}

Cuadro 6. Resultados del factor reumatoide

\begin{tabular}{lcccc}
\hline $\begin{array}{l}\text { Factor } \\
\text { reumatoide }\end{array}$ & Frecuencia & Porcentaje & $\begin{array}{c}\% \\
\text { válido }\end{array}$ & $\begin{array}{c}\% \\
\text { acumulado }\end{array}$ \\
Negativos & 34 & 97 & 97 & 97 \\
Positivos & 1 & 3 & 3 & 100 \\
Total & 35 & 100 & 100 &
\end{tabular}


Cuadro 7. Otros estudios diagnósticos realizados

\begin{tabular}{|c|c|c|c|c|}
\hline \multicolumn{4}{|c|}{ Anticuerpos antinucleares } & \\
\hline Dímero D & Frecuencia & Porcentaje & Válido \% & Porcentaje acumulado \\
\hline \multicolumn{5}{|l|}{ Células LE } \\
\hline \multicolumn{5}{|l|}{$\mathrm{C} 3$ y $\mathrm{C} 4$} \\
\hline \multicolumn{5}{|l|}{ T3, T4 y TSH } \\
\hline \multicolumn{5}{|c|}{ Helicobacter pylori } \\
\hline \multicolumn{5}{|l|}{ Valores } \\
\hline Negativos & 100 & 100 & 100 & 100 \\
\hline Positivos & 0 & 0 & 0 & 0 \\
\hline Total & 35 & 100.0 & 100.0 & 100.0 \\
\hline
\end{tabular}

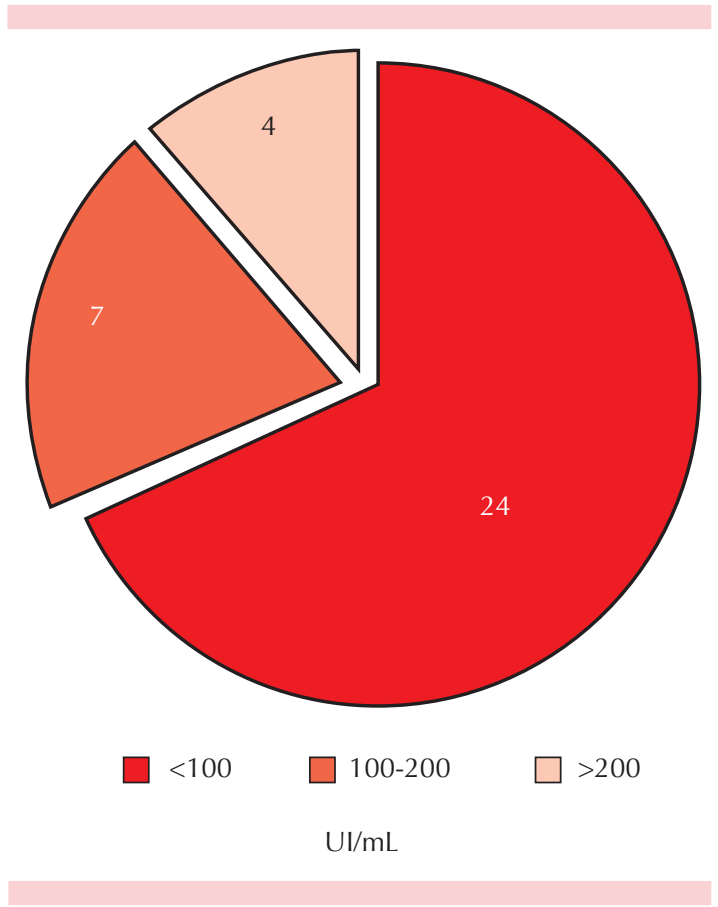

Figura 2. Concentraciones de IgE en población con urticaria crónica espontánea.

tablas de contingencia, en las que demostramos que no hay correlación significativa entre la positividad de la prueba ASST y la existencia de anticuerpos antitiroideos; todos los pacientes positivos a la prueba AAT eran mujeres.

\section{DISCUSIÓN}

Se confirma la predisposición a la urticaria crónica espontánea en el sexo femenino al encontrar el mayor porcentaje de manifestación en este género (27 de 35); por los datos obtenidos podemos confirmar que la edad usual de aparición es entre 40 y 50 años.

Los cuadros presentados eran severos, en ronchas y en prurito, de acuerdo con la severidad reportada por la escala UAS7.

En apoyo a las guías de tratamiento de la urticaria crónica espontánea podemos confirmar que los estudios para llegar a una conclusión diagnóstica son limitados, al encontrar que la prueba de suero autólogo puede ser positiva; sin embargo, esto no representa una verdadera relación con autoinmunidad, ni con la prueba ASST, lo que podría mejorar con la búsqueda de anticuerpos IgG dirigidos contra los receptores alfa de alta afinidad de IgE (FcERI). Además, los anticuerpos antitiroideos pueden estar elevados en un bajo porcentaje de casos, pero estos pacientes normalmente son eutiroideos y la correlación de estos anticuerpos con la prueba de suero autólogo no es significativa. 


\section{CONCLUSIONES}

Los pacientes con urticaria crónica espontánea tienen cuadros severos, como único rasgo de autoinmunidad, la prueba de suero autólogo y los anticuerpos antitiroideos fueron positivos en 4 de 35 pacientes estudiados, por lo que se concluye que la urticaria crónica espontánea no necesariamente tiene una relación con autoinmunidad, como se creyó durante mucho tiempo, además de que el estudio de dímero $\mathrm{D}$, factor reumatoide anticoagulante lúpico, anticuerpos antinucleares, prueba de Helicobacter pylori, perfil tiroideo y complemento sólo representan un gasto y no un apoyo diagnóstico verdadero.

\section{REFERENCIAS}

1. Aguilar Hinojosa N, Segura MHinoj N, Del Rivero HernRiverL. Urticaria crónica autoinmune. Alergia, Asma e Inmunol Ped 2011;20:82-87.

2. Guillén Escalón J, Vargas Rosas MA, Mendoza Magaña E, Zepeda Ortega B y col. Urticaria y angioedema. Rev Alerg Méx 2007;54:54-65.

3. Larenas Linnemann D. Urticaria y Angioedema en Pediatría. CCAP 2011;11:28-41.

4. Ghaffari J, Farid Hossaini R, Rafatpanah H, Jabbari Azad F, Shahmohammadi S. Chronic urticaria in children: etiologies, clinical manifestations, diagnosis and treatment. J Pediatr Rev 2013;1:55-68.

5. Sánchez-Borges M, Asero R, Ansotegui IJ, Baiardini I, Scientific and Clinical Issues Council, et al. Diagnosis and treatment of urticaria and angioedema. WAO J 2012;5:125147.

6. Sánchez-Saldaña L. Urticaria crónica. Dermatol 2012;23:78-97.

7. Ordaz Molina J, Soriano Hernández MI, Husein El Ahmed H, Espiñera Carmona MJ, Arias Santiago S. Angioedema: diagnóstico y tratamiento. Actual Med 2010;95:25-34.

8. Zuberbier T, Bindslev-Jensen C, Canonica W, Grattan CE, et al. EAACI/GA2LEN/EDF guideline: management of urticaria. Allergy 2006;61:321-331.

9. Rojas Sotelo M. Urticaria maligna. Acta Médica Grupo Ángeles 2013;11:132-136.

10. Viswanathan RK, Biagtan MJ, Marthur SK. The role of autoimmune testing in chronic idiopathic urticaria. Ann Allergy Asthma Immunol 2012;108:337-341.

11. Nuzzo V, Tauchmanova L,Colasanti P, et al. Idiopathic chronic urticaria and thyroid autoimmunity: experience of a single center. Dermatoendocrinol 2011;3:255-258.

12. Powell RJ, Du Toit GL, Siddiquez N, Leech SC, et al. BSACI guidelines for the management of chronic urticaria and angio-oedema. Clin Exp Allergy 2013;37:631-650.

13. Chomicience A. Chronic urticaria and thyroid autoimmunity markers. Central Eur J Med 2012;7:736-741.

14. Missakal RF, Penatti HC, Silvares MR, Nogueira CR, Mazeto $\mathrm{GM}$. Autoimmune thyroid disease as a risk factor for angioedema in patients with chronic idiopathic urticaria: a case-control study. Sao Paulo Med J 2012;130:294-299.

15. Domínguez Cardosa MC, Durañones Góngora $S$, Clares Porchet MC, Medina Ferrer R, Robert Tamayo V. Niveles de respuesta autoinmunitaria por anticuerpos antinucleares en pacientes con infecciones virales. Medisan 2012;16:1753-1760.

16. Stitt JM, Dreskin SC. Urticaria and autoimmunity: where are we now? Curr Allergy Asthma Rep 2013;13,555-562.

17. Aguilar-Hinojosa NK, Segura-Méndez NH, Lugo-Reyes SO. Correlación de la gravedad de urticaria crónica y calidad de vida. Rev Alerg Mex 2012;59:180-186. 